\title{
Segmental Difference in Vasoreactivity of the Human Right Gastroepiploic Artery
}

\author{
Takeshi Kinoshita, MD, PhD; Masashi Tawa, PhD; Tomoaki Suzuki, MD, PhD; \\ Tohru Asai, MD, PhD; Tomio Okamura, MD, PhD
}

\begin{abstract}
Background: The gastroepiploic artery (GEA) plays an important role in the era of multiple arterial revascularization, but spasm is a major matter of concern. The internal thoracic artery has been shown to have a strong tendency to spasm in its distal bifurcating part, whereas the segmental difference in vasoreactivity of the GEA has never been performed.
\end{abstract}

\begin{abstract}
Methods and Results: The full length of the GEA obtained from 21 patients undergoing a total gastrectomy was divided into 3 sections: proximal ( $5 \mathrm{~cm}$ from the origin), middle, and distal $(5 \mathrm{~cm}$ from the end). Concentration-response curves for vasoconstrictors (phenylephrine, prostaglandin F2 $a$, and endothelin-1) and vasodilators (carperitide, nitroglycerin, and nifedipine) were then established using organ baths. All the vasoconstrictors and vasodilators produced concentration-dependent responses in each section. As the concentration of the vasoconstrictors increased, segments at the distal section showed a significantly greater contraction than those at the middle and proximal sections regardless of the type of vasoconstrictor. The effective concentration of drugs that caused $50 \%$ of the maximal response for endothelin-1 was significantly greater in the distal section than that in the proximal sections. No significant difference was found in vasodilators-induced relaxation.
\end{abstract}

Conclusions: The contractility increases toward to the end of the GEA. Clinically, the distal portion of the GEA should be trimmed off and not be used as an anastomotic site wherever possible.

Key Words: Gastroepiploic artery; Internal thoraric artery; Spasm

$\mathbf{T}$ he optimal grafting strategy for multi-vessel coronary disease remains controversial. In these circumstances, the right gastroepiploic artery (RGEA) plays a certain role in revascularization, especially for the posterior wall of the heart. One prime benefit of the RGEA is that it can be used as an in situ graft. This strategy potentially contributes to reducing the incidence of postoperative stroke by eliminating aortic clamping if in-situ RGEA is teamed with bilateral internal thoracic artery (ITA) grafts in the off-pump surgery., ${ }^{1,2}$ Another feature is that graft patency of the RGEA is equal to or higher than that of the saphenous vein. Recent reports show that the long-term patency rate of the non-skeletonized RGEA ranged from $82 \%$ to $86 \%$ at 5 years $^{3-5}$ and that of skeletonized RGEA is $94.7 \%$ at 5 years and $90.2 \%$ at 8 years. ${ }^{6}$ In contrast, one major concern of the RGEA graft is spasm, which is wellrecognized and can occur during or immediately after graft harvest. ${ }^{7.8}$ It's been reported that the contractility of ITA grafts is variable along its full length and that its distal section has the highest reactivity, indicating a strong tendency of spasm, ${ }^{-11}$ whereas the segmental variability of vasoreactivity of the RGEA has never been performed. The present study was designed to examine the segmental variability in vasoreactivity between the proximal, middle, and distal sections of the human RGEA.

\section{Methods}

The Human Ethics Committee of Shiga University of Medical Science approved the use of human blood vessels as well as the experimental protocol used in the present study (Approval no. 25-169). Written informed consent was obtained from each patient.

\section{Vessel Preparation}

The full length of the RGEA was obtained from 21 Japanese patients undergoing a total gastrectomy who were shown to have no cardiac disease on preoperative examination. The RGEA was harvested from its origin at the gastroduodenal artery to its terminal anastomosis with the left gastroepiploic branch, immediately placed in a container with Bretschneider's histidine-tryptophan-ketoglutarate solution (Custodiol HTK; Köhler Chemie GmbH, Bensheim, Germany) maintained at $4^{\circ} \mathrm{C}$, and transferred to the laboratory as soon as possible. The mean length of the RGEA was $23 \pm 4 \mathrm{~cm}$. The adherent connective tissue was carefully dissected and 15-mm-long segments were taken from the proximal, middle, and distal sections of the

Received September 12, 2017; accepted November 21, 2017; released online December 13, 2017 Time for primary review: 32 days Division of Cardiovascular Surgery, Department of Surgery (T.K., T.S., T.A.), Department of Pharmacology (M.T., T.O.), Shiga University of Medical Science, Otsu, Japan

Mailing address: Takeshi Kinoshita, MD, PhD, Division of Cardiovascular Surgery, Department of Surgery, Shiga University of Medical Science, Setatsukinowa, Otsu 520-2192, Japan. E-mail: kinotake@belle.shiga-med.ac.jp

ISSN-1346-9843 All rights are reserved to the Japanese Circulation Society. For permissions, please e-mail: cj@j-circ.or.jp 
RGEA. The distal section was identified within $5 \mathrm{~cm}$ from the end of the RGEA, proximal section within $5 \mathrm{~cm}$ from the origin of the RGEA, and the middle as midway between the proximal and distal sections. Each 15-mm-long segment was then evenly divided into 3 segments $(5 \mathrm{~mm}$ in length) and helically cut into strips with special care being taken to preserve the endothelium, before randomly assigned to different drugs in an isometric tension study.

\section{Isometric Tension Study}

Each specimen was vertically fixed between hooks in a muscle bath (10-mL capacity) containing modified RingerLocke solution of the following composition: $120 \mathrm{mmol} / \mathrm{L}$ $\mathrm{NaCl}, 5.4 \mathrm{mmol} / \mathrm{L} \mathrm{KCl}, 2.2 \mathrm{mmol} / \mathrm{L} \mathrm{CaCl} 2,1.0 \mathrm{mmol} / \mathrm{L}$ $\mathrm{MgCl} 2,25.0 \mathrm{mmol} / \mathrm{L} \mathrm{NaHCO} 3$, and $5.6 \mathrm{mmol} / \mathrm{L}$ glucose. The bathing media were maintained at a temperature of $37 \pm 0.3^{\circ} \mathrm{C}$, aerated with a mixture of $95 \% \mathrm{O} 2$ and $5 \% \mathrm{CO} 2$, and the $\mathrm{pH}$ was 7.36-7.43. The hook fixing the upper end of the strips was connected to the lever of a forcedisplacement transducer (TB-611T; Nihon Kohden Kogyo, Tokyo, Japan) connected to an amplifier (AP-621G; Nihon Kohden Kogyo). Isometric contractions and relaxations were displayed on a pen recorder. Before starting the experiments, all of the preparations were allowed to equilibrate in the bathing medium for $60-90 \mathrm{~min}$, during which time the solution was replaced every $10-15 \mathrm{~min}$. Resting tension is a key determinant of subsequent contractile response. In a preliminary experiment, changes in developed tension at different resting tensions were examined to see where the greatest change in developed tension would occur. We took 3- to 4-cm-long segment from the middle section, then divided it evenly into 6 helical strips, and randomly assigned them to different resting tensions (1.0, $1.5,2.0,2.5,3.0$, and $3.5 \mathrm{~g}$ ). A total of 12 patients provided their RGEA for this experiment. After equilibration for $30 \mathrm{~min}$, active tension induced by $30 \mathrm{mmol} / \mathrm{L} \mathrm{KCl}$ solution was recorded. The sample was washed for $30 \mathrm{~min}$ and repeated twice to confirm reproducibility. The largest increase in active tension was seen in $1.5 \mathrm{~g}$ of resting tension (Figure S1). The next largest difference was observed at $1.0 \mathrm{~g}$ and $2.0 \mathrm{~g}$. The weakest responses were observed at $3.0 \mathrm{~g}$. Based on this result, the resting tension applied to each preparation was adjusted to $1.5 \mathrm{~g}$ in the present study. Contractility was expressed as a relative value of contraction induced by $30 \mathrm{mmol} / \mathrm{L} \mathrm{KCl} .{ }^{12}$ The advantage of this expression is to normalize the contraction by the response to a standard vasoconstrictor and to eliminate the possible differences caused by other factors such as the amount of smooth muscle cells. Integrity of the endothelium was histologically verified by en-face staining of the luminal surface using silver nitrate solution after the isometric tension study (Figure S2). ${ }^{13}$

\section{Measurements}

Contraction by Phenylephrine, Prostaglandin F2a, and Endothelin-1 Two types of spasmogens for arterial grafts has been suggested by He et al. ${ }^{14}$ Type I includes endothelin, prostanoids, and $\alpha 1$-adrenoceptor agonists, the most potent vasoconstrictors that induce strong contraction of arterial grafts even when the endothelium is intact. Type II vasoconstrictors (such as 5-hydroxytryptamine) only induce a weak vasoconstriction when the endothelium is intact. We tested 3 type I spasmogens in the experimental protocol (phenylephrine, prostaglandin F2 $\alpha$, and endothelin-1). At the start of the experiment, the tissues were contracted

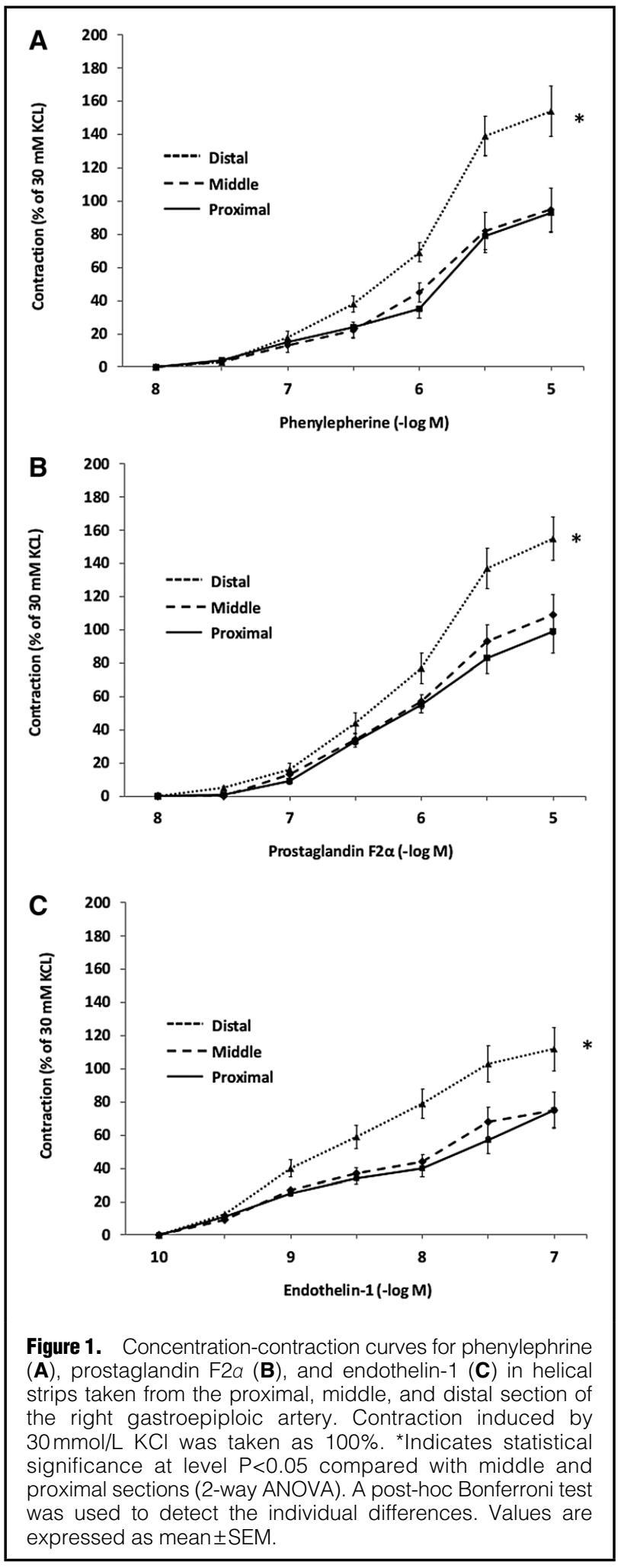

twice with $30 \mathrm{mmol} / \mathrm{L} \mathrm{KCl}$ followed each time by repeated washout with the solution. The second response was taken as an index of the contractile ability. Concentrationresponse curves for phenylephrine $\left(10^{-8}\right.$ to $\left.10^{-5} \mathrm{~mol} / \mathrm{L}\right)$, prostaglandin $\mathrm{F} 2 \alpha\left(10^{-8}\right.$ to $\left.10^{-5} \mathrm{~mol} / \mathrm{L}\right)$, and endothelin-1 $\left(10^{-10}\right.$ to $\left.10^{-7} \mathrm{~mol} / \mathrm{L}\right)$ were then established in helical strips 


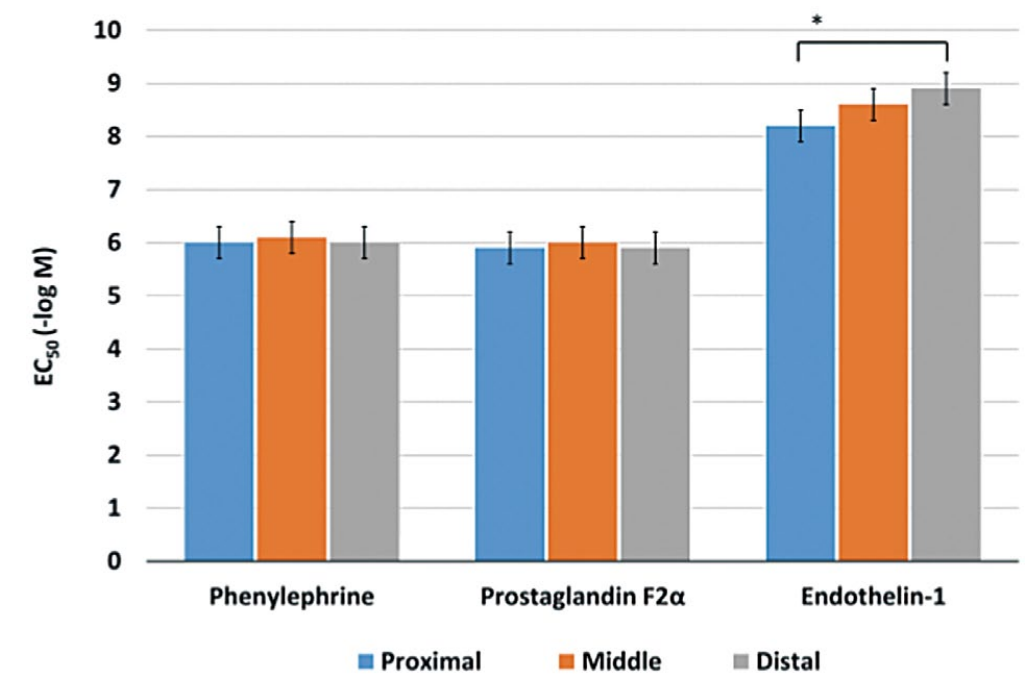

Figure 2. The effective concentration of drugs that caused $50 \%$ of maximal response (EC50) values for phenylephrine, prostaglandin F2a, and endothelin-1 in helical strips taken from the proximal, middle, and distal sections of the right gastroepiploic artery. Mean levels between the 3 groups were compared by using the 1 -way ANOVA. A post-hoc Bonferroni test was used to detect the individual differences. Values are expressed as mean \pm SEM. *Indicates statistical significance at level $P<0.05$. The effective concentration of vasodilators that caused $50 \%$ of maximal response was defined as $\mathrm{EC}_{50}$.

prepared from the proximal, middle, and distal sections by adding the drug directly to the bathing media in cumulative concentrations. Only one curve was obtained from each strip. The effective concentration of drugs that caused $50 \%$ of maximal response (Emax) was defined as $\mathrm{EC}_{50}$. The $\mathrm{EC}_{50}$ was determined from each concentration-response curve by a logistic, curve-fitting equation: $\mathrm{E}=\mathrm{MA}^{\mathrm{P}} /\left(\mathrm{A}^{\mathrm{P}}+\mathrm{K}^{\mathrm{P}}\right)$, where $\mathrm{E}$ is response, $\mathrm{M}$ is maximal response, $\mathrm{A}$ is concentration, $\mathrm{K}$ is $\mathrm{EC}_{50}$, and $\mathrm{P}$ is the slope parameter. ${ }^{15}$

Relaxation by Carperitide, Nitroglycerin, and Nifedipine Helical strips prepared from the distal, middle, and proximal sections of the RGEA were contracted with phenylephrine. After the contraction reached a plateau, concentrationresponse curves for carperitide $\left(10^{-11}\right.$ to $\left.10^{-7} \mathrm{~mol} / \mathrm{L}\right)$, nitroglycerin $\left(10^{-11}\right.$ to $\left.10^{-5} \mathrm{~mol} / \mathrm{L}\right)$, and nifedipine $\left(10^{-11}\right.$ to $10^{-5} \mathrm{~mol} / \mathrm{L}$ ) were obtained by adding the drug directly to the bathing media in cumulative concentrations. Only one concentration-response curve was obtained in each strip. At the end of each experiment, $0.1 \mathrm{mmol} / \mathrm{L}$ papaverine was added to induce the maximal relaxation, which was taken as $100 \%$ for relaxation induced by the agonist as previously described. ${ }^{16}$

\section{Statistical Analysis}

Concentration-contraction curves were compared by using 2-way analysis of variance (ANOVA) for repeated measures. Post-hoc Bonferroni test was used to detect the individual differences. The sphericity assumption was confirmed by the Mauchly test in ANOVA analyses. All statistical testing was 2-sided. Results were considered statistically significant at a level of $\mathrm{P}<0.05$. All analyses were performed with the SPSS statistical package version 21.0 (SPSS Inc., Chicago, IL, USA).

\section{Results}

Figure 1 shows segmental differences in contraction by phenylephrine, prostaglandin F $2 \alpha$, and endothelin-1. Phenylephrine, prostaglandin F2 $\alpha$, and endothelin-1 produced concentration-dependent contraction in strips taken from the distal, middle, and proximal sections of the RGEA. As the concentration of the vasoconstrictors increased, strips at the distal section showed a significantly greater contraction than those at the middle and proximal sections. The Emax for phenylephrine was $154 \pm 11 \%$ at distal, $92 \pm 13 \%$ at middle, $88 \pm 13 \%$ at proximal sections (2-way ANOVA, $\mathrm{P}<0.05)$. The respective values for prostaglandin $\mathrm{F} 2 \alpha$ and endothelin-1 were $150 \pm 12 \%$ at distal, $102 \pm 12 \%$ at middle, $98 \pm 13 \%$ at proximal sections (2-way ANOVA, $\mathrm{P}<0.05$ ), and Emax: $106 \pm 9 \%$ at distal, $72 \pm 11 \%$ at middle, $73 \pm 10 \%$ at proximal sections ( 2 -way ANOVA, $\mathrm{P}<0.05)$. The effective concentration of drugs that caused $50 \%$ of maximal response $\left(\mathrm{EC}_{50}\right)$ of endothelin-1 was significantly lower in the distal section than in the proximal sections $(-8.9 \pm 0.3$ vs. $-8.2 \pm 0.3 \log \mathrm{M}$, Bonferroni post-hoc test, $\mathrm{P}<0.05)$, indicating that the sensitivity to endothelin-1 was 5.0-fold higher in the distal section than in the middle and proximal sections (Figure 2). Figure 3 shows the segmental differences in relaxation by carperitide, nitroglycerin, and nifedipine. All the vasodilators caused a concentration-dependent relaxation response, and no significant segmental difference was found between the proximal, middle, and distal sections.

\section{Discussion}

The present study has 3 major findings. First, the contraction induced by phenylephrine, prostaglandin F $2 \alpha$, and endothelin-1 was significantly greater at the distal section than at the middle and proximal sections of the RGEA obtained from patients undergoing total gastrectomy. Second, the sensitivity to endothelin-1 was significantly higher at the distal section than at the middle and proximal sections. Third, no significant difference was observed in relaxation response to sodium nitroprusside between the 3 sections.

We often face vasospasm in the distal end of the RGEA with a small lumen diameter rather than in the middle and proximal sections during surgery. The present study may provide scientific backing for our empirical observation. The important point from clinical perspectives is that the distal portion of the RGEA should be trimmed off and not be used as an anastomotic site wherever possible. In order 
to do that, it is essential to explore the proximal potion of the RGEA to the level of the pylorus and to harvest an adequate length to prevent excessive tension after grafting. Removal of the surrounding tissue (skeletonization) makes the RGEA longer and larger ${ }^{17,18}$ so that it can be anastomosed at a more proximal position than the non-skeletonized RGEA.

Segmental variability in contractility has been examined in human ITA by He et al. ${ }^{11}$ They tested the reactivity of ITA grafts taken from patients undergoing coronary artery bypass grafting $(\mathrm{CABG})$ and showed that the contraction force was greater in the distal section than in other sections for norepinephrine and endothelin-1, but no differences were found for potassium, U46619 (a thromboxane A2 receptor agonist), or glyceryl trinitrate. They also demonstrated that the sensitivity for U46619 was 100-fold higher in the distal than in the middle section. These results are almost consistent with the present study results. A histological study on the RGEA obtained at autopsy from a patient who had died of non-cardiac diseases has shown that the media is muscular with rare elastic fibers, the thickness of the media and the luminal diameter become thinner and narrower distally, and the degree of intimal hyperplasia gradually decreases along its course. ${ }^{19}$ This histological study does not reveal mechanisms to explain the segmental variability of contractility. The RGEA is considered a visceral artery supplying blood to visceral organs. Physiologically, a higher contractility of visceral arteries compared to somatic arteries such as ITA is considered responsible because blood flow of the splanchnic artery enormously changes under various circumstances to accommodate the function of the stomach.

The study has a number of potential limitations. First, all enrolled subjects were Japanese patients who underwent total gastrectomy and shown to have no cardiac disease on preoperative examination, which limits the generality of the findings, and interpretation of the results should be carefully adopted for patients undergoing CABG. Second, the in vitro design has limitations in the clinical implications, but it allows us to simplify various complex factors that may influence the evaluation of a particular pharmacological agent and focus on the specific effect of the agent on the tissue. Third, we defined each section after the example report by $\mathrm{He}$ et $\mathrm{al},{ }^{11}$ in which the middle section was defined as at least $4 \mathrm{~cm}$ from the distal bifurcation or $4 \mathrm{~cm}$ from the origin of the ITA from the subclavian artery, and the length of the middle section is $\sim 60 \%$ of the total length $(19.5 \pm 2.4 \mathrm{~cm})$. Arbitrariness, however, cannot be completely denied. Fourth, the segmental difference in endothelial function was not examined. The prevalence of vasospasm in arterial grafts can correlate with their endothelial function. Finally, the effect of perioperative drugs on vascular response was not included in the analysis, but chronic use of oral anti-hypertensive drugs such as calcium antagonists, or intraoperative use of catecholamine or nitroglycerin, might modify the vasoreactivity.

In conclusion, the distal section of the RGEA has greater contractility compared to the middle and proximal sections. This finding indicates that the distal section of the RGEA is the part where spasm easily develops and requires pharmacologic and surgical prevention. The middle and proximal sections are less pharmacologically reactive than the distal section, but these sections are not completely non-reactive passive conduits and also require special care. No significant segmental difference was found in relax-

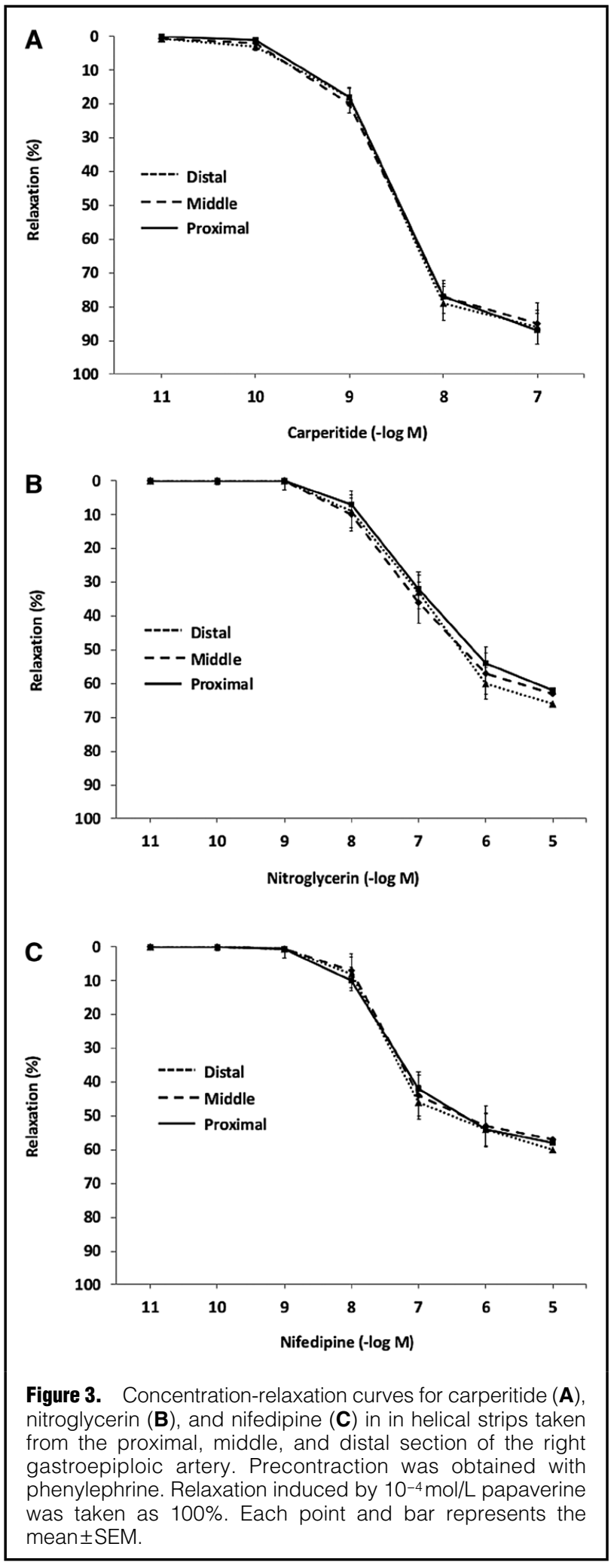

ation by carperitide, nitroglycerin, and nifedipine. These drugs are favored candidates for prevention and reversal of graft spasm when we have no choice but to use the distal part of the RGEA. 


\section{Funding Sources}

This work was supported, in part, by a grant-in-aid for scientific research from the Ministry of Education, Culture, Sport, Science and Technology of Japan (15K19918 and 17K16590).

\section{Conflicts of Interest}

All authors have nothing to disclose with regard to commercial support.

\section{References}

1. Pawliszak W, Kowalewski M, Raffa GM, Malvindi PG, Kowalkowska ME, Szwed KA, et al. Cerebrovascular events after no touch off-pump coronary artery bypass grafting, conventional side-clamp off pump coronary artery bypass, and proximal anastomotic devices: A meta-analysis. J Am Heart Assoc 2016; 18: $\mathrm{e} 002802$.

2. Moss E, Puskas JD, Thourani VH, Kilgo P, Chen EP, Leshnower $\mathrm{BG}$, et al. Avoiding aortic clamping during coronary artery bypass grafting reduces postoperative stroke. $J$ Thorac Cardiovasc Surg 2015; 149: $175-180$.

3. Voutilainen S, Verkkala K, Jarvinen A, Keto P. Angiographic 5 -year follow up study of right gastroepiploic artery grafts. Ann Thorac Surg 1996; 62: 501-505.

4. Hirose H, Amano A, Takahashi A. Coronary artery bypass grafting using the gastroepiploic artery in 1,000 cases. Ann Thorac Surg 2002; 73: 1371-1379.

5. Suma H, Tanabe H, Takahashi A, Horii T, Isomura T, Hirose $\mathrm{H}$, et al. Twenty years experience with the gastroepiploic artery graft for CABG. Circulation 2007; 116: I188-I191.

6. Suzuki T, Asai T, Nota H, Kuroyanagi S, Kinoshita T, Takashima N, et al. Early and long-term patency of in situ skeletonized gastroepiploic artery after off-pump coronary artery bypass graft surgery. Ann Thorac Surg 2013; 96: 90-95.

7. Suma H. Spasm of the gastroepiploic artery graft. Ann Thorac Surg 1990; 49: 168-169.

8. Mills NL, Hockmuth DR, Everson CT, Robart CC. Right gastroepiploic artery used for coronary artery bypass grafting: Evaluation of flow characteristics and size. J Thorac Cardiovasc Surg 1993; 106: 579-585.

9. He GW. Contractility of the human internal mammary artery at the distal section increases toward the end: Emphasis on not using the end of the internal mammary artery for grafting. $J$ Thorac Cardiovasc Surg 1993; 106: 406-411.

10. He GW, Ryan WH, Acuff TE, Yang CQ, Mack MJ. Greater contractility of internal mammary artery bifurcation: Possible cause of low patency rates. Ann Thorac Surg 1994; 58: 529-532.

11. He GW, Acuff TE, Yang CQ, Ryan WH, Mack MJ. Middle and proximal sections of the human internal mammary artery are not "passive conduits". J Thorac Cardiovasc Surg 1994; 108: 741 746.

12. Shinozaki K, Ayajiki K, Nishio Y, Sugaya T, Kashiwagi A, Okamura T. Evidence for a causal role of the renin-angiotensin system in vascular dysfunction associated with insulin resistance. Hypertension 2004; 43: 255-262.

13. Abrol RP, Hughes VM, Krueger CA, Cook DA. Detection of endothelium in cerebral blood vessels. J Pharmacol Methods 1984; 12: 213-219.

14. He GW, Yang CQ, Starr A. Overview of the nature of vasoconstriction in arterial grafts for coronary operations. Ann Thorac Surg 1995; 59: 676-683.

15. He GW, Rosenfeldt FL, Buxton BF, Angus JA. Reactivity of human isolated internal mammary artery to constrictor and dilator agents: Implications for treatment of internal mammary artery spasm. Circulation 1989; 80: I141-I150.

16. Shinozaki K, Nishio Y, Okamura T, Yoshida Y, Maegawa H, Kojima $\mathrm{H}$, et al. Oral administration of tetrahydrobiopterin prevents endothelial dysfunction and vascular oxidative stress in the aortas of insulin-resistant rats. Circ Res 2000; 87: 566-573.

17. Calafiore AM, Vitolla G, Iaco AL, Fino C, Di Giammarco G, Marchesani F, et al. Bilateral internal mammary artery grafting: Midterm results of pedicled versus skeletonized conduits. Ann Thorac Surg 1999; 67: 1637-1642.

18. Gaudino M, Trani C, Glieca F, Mazzari MA, Rigattieri S, Nasso $\mathrm{G}$, et al. Early vasoreactive profile of skeletonized versus pedicled internal thoracic artery grafts. J Thorac Cardiovasc Surg 2003; 125: $638-641$.

19. van Son JA, Smedts FM, Yang CQ, Mravunac M, Falk V, Mohr FW, et al. Morphometric study of the right gastroepiploic and inferior epigastric arteries. Ann Thorac Surg 1997; 63: 709-715.

\section{Supplementary Files}

\section{Supplementary File 1}

Figure S1. Box-and-whisker plots comparing tension induced by $30 \mathrm{mmol} / \mathrm{L} \mathrm{KCl}$ at different resting tensions.

Figure S2. Typical example of en-face staining of the luminal surface using silver nitrate solution in endothelium-intact (Left panel) and -denuded (Right panel) gastroepiploic artery strips (bar $=50 \mathrm{~mm}$ ).

Please find supplementary file(s);

http://dx.doi.org/10.1253/circj.CJ-17-0943 